- Porphyria is a rare metabolic disease

- Certain drugs precipitate acute attacks - including those used commonly in dentistry

- Specialist advice is essential in the management of these patients

- Anxiety associated with a medical problem can complicate patient management

\title{
The management of porphyria in dental practice
}

\author{
G. J. Brown ${ }^{1}$ and R. R. Welbury ${ }^{2}$
}

From time to time a patient may attend your practice with a systemic condition that you may or may not remember from the small print of your undergraduate text books. This paper describes one such systemic condition, porphyria, and its dental management. This paper also describes the use of relative analgesia as an aid to anxiety management in porphyria.

\section{Classification}

Porphyrias are a mainly inherited group of metabolic disorders which affect the haem biosynthesis pathway as a result of an enzyme defect. This can result in the accumulation or the excretion of porphyrins which are purple-red pigments of a crystalline nature. The pathological classification is based on the stage of haem biosynthesis and the specific enzyme defect: ${ }^{2}$

1. ALA dehydratase deficiency porphyria: enzyme ALA dehydratase

2. Acute intermittent porphyria: enzyme PBG dehydratase

3. Congenital erythropoietic porphyria: enzyme uroporphyrinogen cosynthase

4. Cutaneous hepatic porphria: enzyme uroporphyrinogen decarboxylase

5. Hereditary coprophyria: enzyme coproporphyinogen oxidase

6. Variegate porphyria: enzyme protoporphyrinogen oxidase

7. Erythropoietic protopophyria: enzyme ferrochelatase

A common factor in all types of porphyria is an increase in the rate limiting enzyme five aminolaevulinic (ALA) synthe-

${ }^{1}$ Senior Dental Officer, Tees and North East Yorkshire NHS Trust; ${ }^{2}$ Professor of Paediatric Dentistry, Glasgow Dental Hospital and School

Correspondence to: $\mathrm{Mr} \mathrm{G} J$ Brown, Department of

Orthodontics, The Dental Hospital, Richardson Road,

Newcastle upon Tyne NE2 4AZ

E-mail:g.j.brown@tinyworld.co.uk

\section{Refereed Paper}

Received 21.08.01; Accepted 18.02.02

๑) British Dental Journal 2002; 193: 145-146 sis which initiates the haem biosynthesis.

Porphyria is commonly classified clinically into acute or non acute.

The acute porphyrias include: ${ }^{2}$

- ALA dehydratase deficiency porhpyria

- Acute intermittent porphyria

- Variegate porphyria.

- Hereditary coproporphria

During acute episodes severe abdominal pain is often the most significant finding and can be mistaken for an acute abdominal condition. In addition, limb weakness, cardiovascular changes, neuropsychiatric, and photosensitive skin changes (with the exception of acute intermittent porphyria) are common.

Acute attacks can be precipitated by a wide range of common drugs and a current list of safe and unsafe drugs is essential. Often patients with porphyria carry such lists themselves, alternatively the Dental Practitioners Formulary and the British National Formula$r y^{3}$ can provide a useful guide. In addition, the Welsh Drug Information Centre is an excellent source of information.

However, many patients can have acute attacks without taking or having any drugs administered. It is thought these patients are more susceptible because of infections, alcohol, programmed or nonprogrammed weight loss, smoking, endogenous hormonal changes and being female of child bearing age (a four-fold increase). If an acute attack is suspected expert medical help should be sought and arrangements made to transfer the patient to an appropriate facility immediately.

Prevention of an attack is essential and it is important for healthcare profes- sionals and patients to understand the following: ${ }^{2}$

1. Safe drugs only should be used

2. Patients should be educated about precipitating factors

3. Alcohol and smoking should be restricted or discouraged

4. Patients should wear a medic-alert device

5. Dieting and weight loss should be avoided

6. Specialist advice regarding menstruation should be sought if it is thought this may precipitate an acute attack

7. Barrier creams should be used to prevent photosensitivity reactions

8. Pregnancy should be postponed until the disease is under control ${ }^{5}$

During the administration of a drug it should remembered that any drug which increases the synthesis of cytochrome P450 enzymes in the liver will also increase the synthesis of haem. This can result in an acute attack. However, this is not the complete story as some drugs which does not induce P450 enzymes and haem synthesis may also precipitate porphyria so it is essential to always refer to a 'safe drug' reference text.

\section{The non-acute porphyrias}

These are known as cutaneous porphyrias. Photosensitising porphyrins are deposited in the upper dermal layer which are responsible for the characteristic skin lesions. The types of non-acute (cutaneous) porphyria are:

- Congenital Erythropoietic Porphyria (Gunthers Disease) 
- Erythropoietic Protoporphyria.

- Porphyria Cutanea Tarda (Cutaneous Hepatic Porphyria)-inherited or acquired.

These chronic porphyrias will not be discussed further in this report. However, the dental manifestations are summarised by Rayne, J. (1967) and Trodahl et al. (1972). 6,7

\section{DISCUSSION}

Although porphyria is a rare metabolic disorder it can still be encountered in general practice. This paper is primarily aimed at practitioners wishing to treat patients in the general practice setting. Most of the commonly used local anaesthetics in general practice contain sodium metabisulphite, which can precipitate an acute episode in patients with porphyria. However, bupivacaine does contain sodium metabisulphite, and is thought to be safe in patients with porphyria . In the list of drugs to be avoided in porphyria in the Dental Practioners Formulary, it is advised that lidocaine may be used with caution. ${ }^{3}$

This note suggests by its implication that the community or practice setting is not the place to use lidocaine and this was the reason for seeking an alternative local anaesthetic in this case. Bupivacaine is supplied in a glass vial with or without adrenaline and its onset of action can take up to 30 minutes. However, the usual figure quoted in the literature is 10 minutes. The latter has a bearing on the timing of the local anaesthetic delivery. In our case, the local anaesthetic was given as soon as the patient felt relaxed using the inhalation sedation, approximately 5 minutes after the start of the procedure.

The chemical structure of bupivacaine is similar to that of lidocaine with the amine group being butyl piperidine in bupivacaine. $^{1}$

The concentration of nitrous oxide can be tailored to the individual. In this case the concentration did not exceed 40\% and resulted in the patient feeling dissociated and relaxed. How much of an analgesic effect the nitrous oxide played in this patient was difficult to tell, but previous authors have reported varying degrees of analgesia at this concentration. It should be remembered that in order to achieve total analgesia a concentration of between $50 \%$ and $70 \%$ nitrous oxide is required. ${ }^{4}$ However, above a concentration of $50 \%$ a small number of patients will enter general anaesthesia. This must be avoided and the most useful

\section{CASE HISTORY}

A 34-year-old man with Variegate form porphyria (Fig.1.) was referred to our anxiety management clinic by a local dental practitioner for treatment of progressive carious lesions. At the initial visit the patient admitted that he had a major anxiety in relation to dental treatment, and this could be related to having previous restorative work, without local anaesthesia. We assumed from this, the previous dentist had recognised the possibility of precipitating an acute episode with local anaesthesia. Following a lengthy discussion, all parties felt the most appropriate method to allow dental treatment would be to use a 'safe' local anaesthetic with nitrous oxide (inhalation sedation) to reduce anxiety. The choice of local anaesthetic in this case was bupivacaine $0.25 \%$ with 1 in 200,000 adrenaline. Our local hospital drug information officer, the

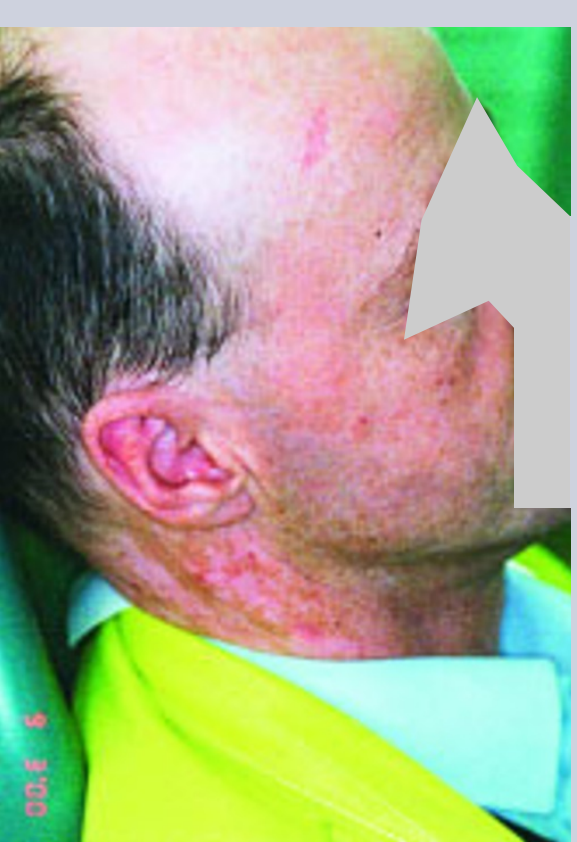

Fig. 1 Cutaneous scarring on the forehead and neck in variegate porphyria Dental Practitioners Formulary ${ }^{3}$ and the Welsh Drug Information Centre ${ }^{2}$ were consulted to ensure both drugs, when used together, were safe. At a subsequent treatment appointment and after a brief explanation of the sequence events, the inhalation sedation was commenced. Following a suitable level of sedation, the local anaesthetic was delivered using an aspirating technique with a 26 gauge needle. The procedure was uneventful. Following a suitable period of recovery the patient was informally interviewed and reported that the whole treatment experience was a vast improvement over previous treatment experiences. Specifically, the patient reported feeling very relaxed during the whole procedure. A number of subsequent appointments were made to allow completion of the treatment, and none of these appointments were broken.

sign to ensure a patient is conscious is the 'open mouth' sign.

The use of nitrous oxide was favoured over intra-venous sedation in this case for a number of reasons. The first was that midazolam is thought to be 'probably safe' (Dental Practitioners Formulary), ${ }^{3}$ hence it was felt that it would be inappropriate to use it in the practice setting or community setting. Secondly, patients with certain porphyrias are prone to skin damage and subsequent secondary infection. Cannulation could precipitate this, which can lead to an acute attack or scarring.

\section{SUMMARY}

Porphyria is a metabolic condition that is rarely seen in general practice. However, its management can be compounded when the patient is also nervous. This paper shows that with appropriate guidance a satisfactory outcome can be achieved in a general practice or community dental setting with minimal inconvenience to the patient.

The Welsh drug information centre, South Cleveland Pharmacy and Mr. A McCoughlin.

1. Hardman J. G., Limbird L. E., Molinoff P. B., Ruddon R. W., Gilman A. G. Goodman and Gilman's. The Pharmacological Basis of Therapeutics. 9th ed. pp 307-328 and pp 331-346. New York: McGraw-Hill, 1996.

2. Adams A. The Welsh drug information centre. ADrug Information Bulletin. Porphyria No.2. 1997.

3. The Dental Practitioners Formulary. pp450. London: BDA, BMA, RPS, 2000-2002.

4. Neal M. J. 1st ed. pp16-17, pp48-51. Medical Pharmacology at a glance. Oxford: Blackwell Scientific Publications, 1987

5. Hope R. A., Longmore J. M., Moss P. A., Warrens A. N. Oxford Handbook of Clinical Medicine. 2nd ed. pp656. Oxford: Oxford University Press, 1989.

6. J. Rayne, Porhyria erythropoietica. Br J Oral Surg 1967; 5: 68-74.

7. J. N. Trodahl, S. Schwartz, R. J. Gorlin. The pigmentation of dental tissues in erythropoietic (congenital) porphyria. J Oral Path 1972; 1: 159-171. 